\title{
HABITAÇÃO E GRANDES EMPREENDIMENTOS: MARCOS DA EXPANSÃO URBANA DE VITÓRIA NA DÉCADA DE 1960
}

\section{Housing And Large Projects: Symbols Of Vitória's Urban Expansion In The 60s}

\author{
Eneida Maria Souza Mendonça \\ Programa de Pós-Graduação em Geografia da Universidade Federal do Espírito Santo \\ eneidamendonca@gmail.com
}

\section{Resumo}

O artigo aborda a expansão urbana e a valorização do solo, tendo como foco a política habitacional e a instalação de empreendimentos de grande porte em Vitória. São examinados: a história da ocupação, a base econômica e a evolução da localização de conjuntos habitacionais e de grandes empreendimentos no território. Nas primeiras seis décadas do século XX, Vitória alcançou hegemonia política na hierarquia estadual. A década de 1960 tornou-se um marco na realidade econômica do estado, que passou de agrícola para industrial, e no processo de urbanização da capital, que assumiu estrutura metropolitana. O estudo demonstrou, por um lado, o distanciamento social das políticas empreendidas, e por outro lado, a inserção do Espírito Santo em circuito econômico mais amplo, acompanhando a dinâmica nacional e internacional.

\section{Palavras-chave}

urbanização, habitação, grandes empreendimentos

\begin{abstract}
This article shows urban expansion and the resulting land value, focusing on housing policies and the setting up major developments in Vitória. The article examines the history of occupancy, the economic base and the evolution of the housing development location and major developments. During the first six decades of the twentieth century Vitória achieved political hegemony in the State hierarchy, establishing as its capital. During the 60s, the State's economic reality, changed from agricultural to industrial and in the urbanization process of the capital that assumed its metropolitan structure. The article showed on one hand the social distancing of the policies undertaken, and on the other hand the insertion of Espirito Santo into a broader economic circuit, following the national and international dynamic.
\end{abstract}

\section{Keywords}


urbanization, housing, major developments.

\section{Introdução}

Este artigo aborda aspectos referentes à expansão urbana e à consequente valorização do solo, tendo como foco a política habitacional executada em Vitória, capital do Espírito Santo, bem como a instalação de empreendimentos de grande porte. Para tanto, são examinados a história da ocupação do lugar, os aspectos relativos à base econômica do estado e a evolução da localização de conjuntos habitacionais e de grandes empreendimentos no território.

A história da ocupação de Vitória é tratada brevemente, pautada especialmente em planos e respectivas memórias explicativas e justificativas. 0 interesse neste aspecto é indicar os motivos de ocupação do sítio, mas, sobretudo assinalar os esforços empreendidos na manutenção em Vitória, do poder político como sede de capitania e posteriormente, capital de estado. Estes esforços significaram até a década de 1960 a manutenção da ocupação urbana do município na ilha de Vitória.

Os aspectos relativos à economia ressaltam a modificação da base econômica marcada pela crise associada à cultura cafeeira desde meados da década de 1950 até a consolidação da grande indústria voltada à siderurgia em meados da década de 1980 (ROCHA e MORANDI, 1991). O intuito da abordagem econômica é de situar a década de 1960 como período intermediário à transição econômica ocorrida no Espírito Santo.

A evolução da localização de conjuntos habitacionais e de grandes empreendimentos acompanhou as mudanças sociais e econômicas em vigência no estado, indicando modificação da estratégia política estabelecida até então, ao inaugurar um processo contínuo de ocupação da área continental do município. A lógica de localização dos conjuntos, bem como dos grandes empreendimentos acompanhou orientação instituída por política em escala nacional.

No que diz respeito à questão habitacional, a orientação nacional correspondeu à política instituída pelo Sistema Nacional de Habitação em 1964 (CINTRA e HADDAD, 1978; SCHMIDT, 1983). No que se refere à localização dos grandes empreendimentos, a relação com a esfera nacional se estabelece como procedimento preliminar aos chamados grandes projetos industriais, instituídos de modo mais incisivo no Espírito Santo, na década seguinte, pelo II Plano Nacional de Desenvolvimento - II PND - (BRASIL, 1974). No que diz respeito às metrópoles brasileiras, Villaça (1998) chama a atenção para a preferência de localização de extensas áreas industriais nas proximidades de vias de significado regional, sejam 
ferrovias ou rodovias. No caso da Grande Vitória, incluída por este autor no quadro das áreas metropolitanas brasileiras, constatou-se que, as áreas industriais relativas aos referidos grandes projetos, além de relacionadas a estas duas modalidades de vias - ferrovias e rodovias - contaram também, com a implantação de novos portos.

Seguindo então, as fontes e os procedimentos metodológicos indicados, é fundamental reconhecer Vitória como uma cidade do período colonial brasileiro, cuja ocupação tem origem, por volta de 1551, a partir da intenção de alcançar melhores condições de defesa que a antiga sede da capitania, Vila Velha, desde 1535. Neste contexto, a ocupação de Vitória ocorreu ao sul da ilha encravada em uma baía, de modo a facilitar a vigilância diante de qualquer natureza de ataque, externo, no caso de estrangeiros, ou interno, no caso de indígenas (NOVAES, s/d; OLIVEIRA, 1975).

Estratégias marcantes de ocupação do território ocorreram durante o período de permanência dos jesuítas no Brasil, ao estabelecerem diversas de suas sedes em Vitória e áreas circundantes e mais recentemente, na segunda metade do século XIX, com a colonização do interior do estado por imigrantes europeus, possibilitando o estabelecimento de uma rede de cidades. No período intermediário entre a expulsão dos jesuítas e a colonização do interior por imigrantes, o Espírito Santo manteve uma economia fraca e inexpressiva e sua capital não ampliou sua ocupação para além da porção sul da ilha.

A alteração deste quadro data do final do século XIX, quando a cultura cafeeira no Espírito Santo, instaurada pelos imigrantes estrangeiros passou a alavancar a economia do estado e possibilitar melhoramentos na capital (CAMPOS JÚNIOR, 1996). Este foi um processo mantido e fortalecido nas primeiras décadas da República, por meio de diversas políticas governamentais e de diversos planos urbanísticos. Dentre estes tem destaque o programa de governo de Muniz Freire que, entre 1892 e 1896, propagou a importância da reestruturação da rede ferroviária, do reaparelhamento do porto e do projeto de um bairro (Figura 1) aos moldes higienistas (CAMPOS JÚNIOR, 1996; MENDONÇA et al. 2009). Os governantes que o sucederam, mesmo que empreendessem políticas específicas, não deixaram de conferir continuidade ao programa estabelecido no início da república, a despeito da diferença quanto ao ritmo das ações desenvolvidas em cada período governamental.

Alterações significativas no quadro econômico ocorreram somente na segunda metade do século XX, com destaque para o período relativo à década de 1960, conforme desenvolvido a seguir. 


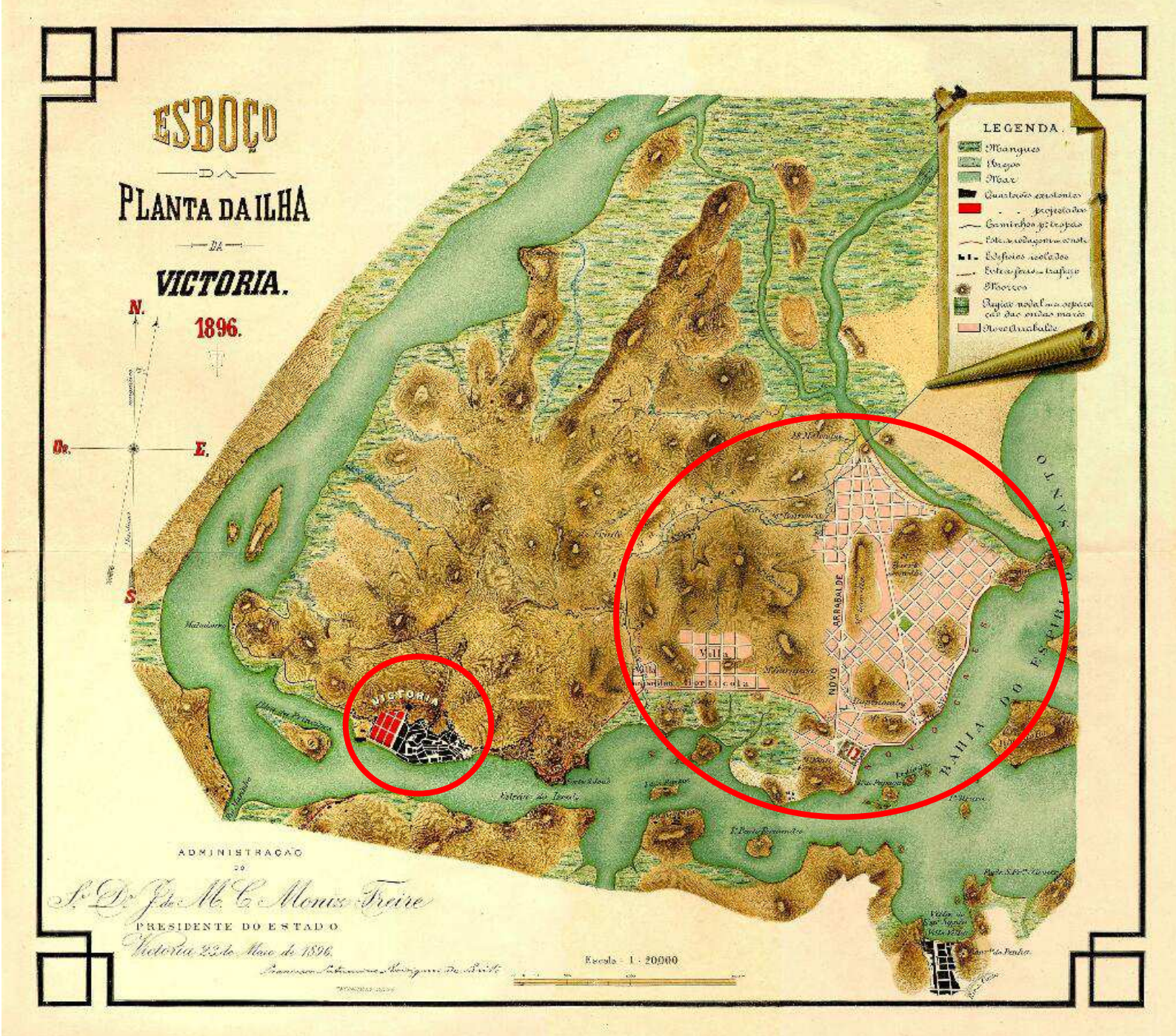

Figura 1 - Mapa de Vitória de 1896 com o bairro projetado a leste e a cidade ao sul. Fonte: Arquivo Público Estadual. Espírito Santo. Brasil.

\section{A década de $\mathbf{1 9 6 0}$ como marco na transição econômica do Espírito Santo}

Durante toda a primeira metade do século $X X$, o café manteve-se como o principal produto do estado do Espírito Santo, cuja dinâmica de produção e exportação teve suporte na modernização da infraestrutura dos sistemas portuário e ferroviário, projetado no final do século XIX (Figura 2).

Quanto ao desenvolvimento urbano da capital, é notável que sua modernização tenha sido financiada pelo comércio de café e que sua expansão tenha seguido o rumo leste, orientada pelo projeto urbanístico também definido na mesma ocasião que as obras do porto e da ferrovia, no governo de Freire.

Neste contexto, nas primeiras seis décadas do século XX, Vitória alcançou hegemonia política na hierarquia estadual, firmando-se como capital, ao mesmo 
tempo em que assumia sua identidade insular, mesmo que para isso tivesse mantido sua expansão associada à construção de aterros (FREITAS, 2004).

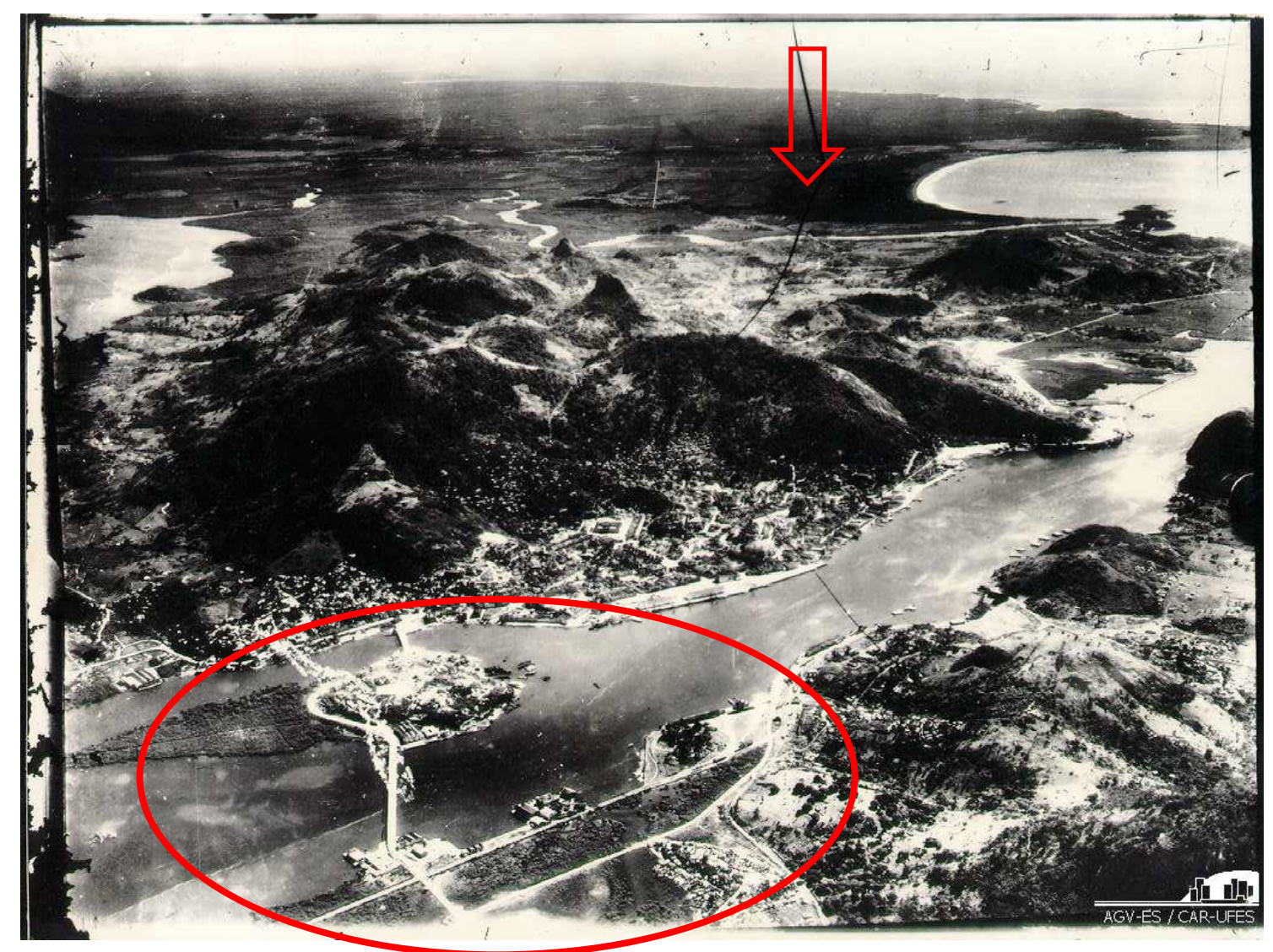

Figura 2 - Vitória na década de 1930. Em primeiro plano, o porto, as pontes e a infraestrutura ferroviária. Ao fundo, a área continental antes da ocupação.

Fonte: Arquivo Geral de Vitória.

No processo evolutivo esboçado durante a década de 1960, esta situação se transformou, tornando este período um marco na realidade econômica do estado e no processo de urbanização da capital.

Para Rocha e Morandi (1991) a transição econômica do Espírito Santo, passando de agroexportador voltado à cultura cafeeira para industrial de grande porte voltado à siderurgia, correspondeu a um processo iniciado em meados da década de 1950 e concluído em meados da década de 1980, quando os complexo industriais referentes à Companhia Siderúrgica de Tubarão (atual ArcellorMittal), à empresa Aracruz Celulose (atual Fibria) e à Samarco Mineradora entraram em funcionamento. No entanto, para estes mesmos autores, do ponto de vista econômico, a década de 1960 abarcou o período em que se acentuou no estado o êxodo rural, em função da crise relacionada à política de erradicação dos cafezais, gerando assim uma crise social sem precedentes no meio rural capixaba.

Deste modo, ao longo da década de 1960 o agravamento da crise cafeeira, que subsistia desde 1955, com a queda de preços internacionais do café, prejudicou 
intensamente a economia do estado, culminando na erradicação dos cafezais, no empobrecimento da população, êxodo rural e consequentemente aumento da população urbana de baixa renda em Vitória e municípios vizinhos. Para Rocha e Morandi (1991, p: 52 e 57),

[...] O programa [de erradicação de cafezais] atingiu todas as áreas produtoras do país, mas algumas tiveram proporcionalmente um número maior de pés erradicados, como foi o caso do Espírito Santo.

[...] a 'economia capixaba' foi a mais profundamente atingida pelo programa de erradicação, [...] A crise social gerada pela erradicação é o aspecto mais ressaltado e se expressou de forma dramática na substancial redução de renda e do emprego, o que provocou o empobrecimento econômico e um vigoroso processo de 'expulsão' da população do campo para as áreas urbanas (Rocha e Morandi, 1991).

O final da década de 1960 apontava para perspectivas quanto à industrialização, a partir de atividades em instalação ao norte de Vitória, contribuindo para o mencionado êxodo, já em curso, em função da crise na agricultura, e atraindo a infraestrutura urbana no vasto território da área continental do município.

Nesta ocasião, grande parte das indústrias brasileiras se concentrava na região da capital paulista, incluindo o ABC - Santo André, São Bernardo e São Caetano -, e na via Dutra, ligação rodoviária entre São Paulo e Rio de Janeiro (Villaça, 1998). Descentralizando, de certo modo esta concentração, mas ainda com localização mantida no sudeste do país, cabe indicar que a implantação dos grandes projetos industriais ao longo da década de 1970 no Espírito Santo, seguindo orientação do Plano Nacional de Desenvolvimento - II PND - (BRASIL, 1974), tornou-se também um motivo para alimentar o êxodo rural, e contribuiu para que a década de 1980 marcasse o fim da transição econômica de agroindústria cafeeira para grande indústria siderúrgica.

Os aspectos socioeconômicos aqui brevemente descritos e característicos do Espírito Santo neste período contribuíram para acelerar o processo de urbanização a partir da década de 1960 e para a instituição de mudanças na política urbana da capital.

\section{A década de 1960 como marco na mudança da política urbana em Vitória}

Do ponto de vista do processo de urbanização, a década de 1960 marcou o rompimento da política de expansão urbana da capital, estabelecida até então, ao longo da República, focada exclusivamente na ilha de Vitória, mesmo que extenso aterro contíguo à ilha tivesse ainda, sido construído, durante a década de 1970 
(MENDONÇA, 1995). A mudança na política de urbanização em Vitória ocorreu especialmente em função da política habitacional adotada na década de 1960, bem como da instalação de equipamentos de grande porte na capital.

Na sequência do vetor de expansão que vinha orientando a ocupação urbana da cidade, a implantação de conjuntos habitacionais, campus universitário e porto, durante a década de 1960, ocorreu a nordeste da ilha, na área continental de Vitória, onde já se localizava desde a década de 1940, o aeroporto (MENDONÇA, 1995).

A despeito das terras no continente de Vitória terem sido loteadas na década de 1950 por particulares, foi constatado, sobretudo através de relatórios da administração municipal, que sua inserção no contexto urbano do município, ocorreu durante a década de 1960, por iniciativa do poder público, através da instalação de atividades de grande porte como a Companhia Vale do Rio Doce (por meio da qual foi construído, em 1966, o porto de Tubarão), o campus da Universidade Federal do Espírito Santo (1969) e pela construção de conjuntos habitacionais de interesse social (a partir de 1966). Os investimentos municipais em infraestrutura urbana eram ainda, entretanto, direcionados objetivamente à ilha de Vitória, mas seguiam gradativamente um percurso, cujo vetor apontava no sentido do continente.

No início da década de 1960 , os investimentos do município voltavam-se para a região oeste e nordeste da ilha de Vitória, e mais intensivamente para o Centro, situado ao sul da ilha. A esta época, Vitória era caracterizada pela ilha e especialmente pelo Centro, mesmo que oficialmente contasse com terras no continente. As obras públicas realizadas na região central e a verticalização aí emergente e pontualmente localizada contribuíam para a imagem metropolitana almejada, contrastando com a dos demais bairros. Em meados da década de 1960 os recursos públicos atingiam os morros, o norte e leste da ilha de Vitória. No final da década de 1960 os investimentos municipais voltavam-se para a drenagem e urbanização de aterros diversos a oeste, sul e sudeste da ilha e também ao bairro projetado a leste da ilha, em finais do século XIX, pelo engenheiro Saturnino de Brito, por encomenda do governador Muniz Freire.

Neste sentido, percebe-se uma aproximação da infraestrutura em relação à área continental. Quanto a este aspecto, constatou-se no orçamento de 1960 a previsão de dotação orçamentária para drenagem em Goiabeiras, provavelmente referindo-se ao povoado existente na área continental, que segundo o balanço correspondente a aquele exercício, não foi utilizada. Apenas no orçamento de 1969, voltou a constar previsão de verbas para urbanização de Goiabeiras, neste momento, provavelmente, já em função dos conjuntos habitacionais. O fato de não ter sido 
localizado o balanço referente a este exercício, dificulta a confirmação quanto à aplicação destes recursos. No entanto, a indicação deste item no orçamento, mesmo através de quantia ínfima se comparada aos recursos destinados a outras regiões, a presença da CVRD e do campus universitário na área continental e a autorização da Câmara para permuta de terras entre proprietários e prefeitura no loteamento Camburi, já demonstravam que crescia a atenção do poder público para com o local.

A CVRD instalou-se em Tubarão, determinando a necessidade de serviços urbanos nesta direção e instituindo desde então, um limite à expansão da cidade no sentido leste. O campus da UFES foi instalado próximo à ponte da Passagem, na estrada do Aeroporto, ao norte do loteamento Camburi, em terrenos do Golf and Country Club de Vitória, expandindo-se através de aterros sobre manguezal no sentido norte (COSTA, s/d). A localização do campus universitário afastado da área central da cidade, além de atender na ocasião, a um padrão instituído no país, no caso específico de Vitória, seguiu e ao mesmo tempo, colaborou para determinar o percurso da expansão urbana no município. Os conjuntos habitacionais construídos em Goiabeiras, Camburi e em Vila Balneário de Camburi, contribuíram para a caracterização do território urbano em formação nesta ocasião no continente. Mesmo considerando que esta caracterização, alcançasse no âmbito municipal, um sentido genérico, conferindo à área continental do município a identidade do distante território dos conjuntos habitacionais, o exame de aspectos arquitetônicos, urbanísticos e socioeconômicos destes conjuntos sugeria já a esta época, a distinção territorial entre Goiabeiras, próximo ao mangue, e Camburi, próximo ao mar, que só mais tarde seria realçada (MENDONÇA, 1995).

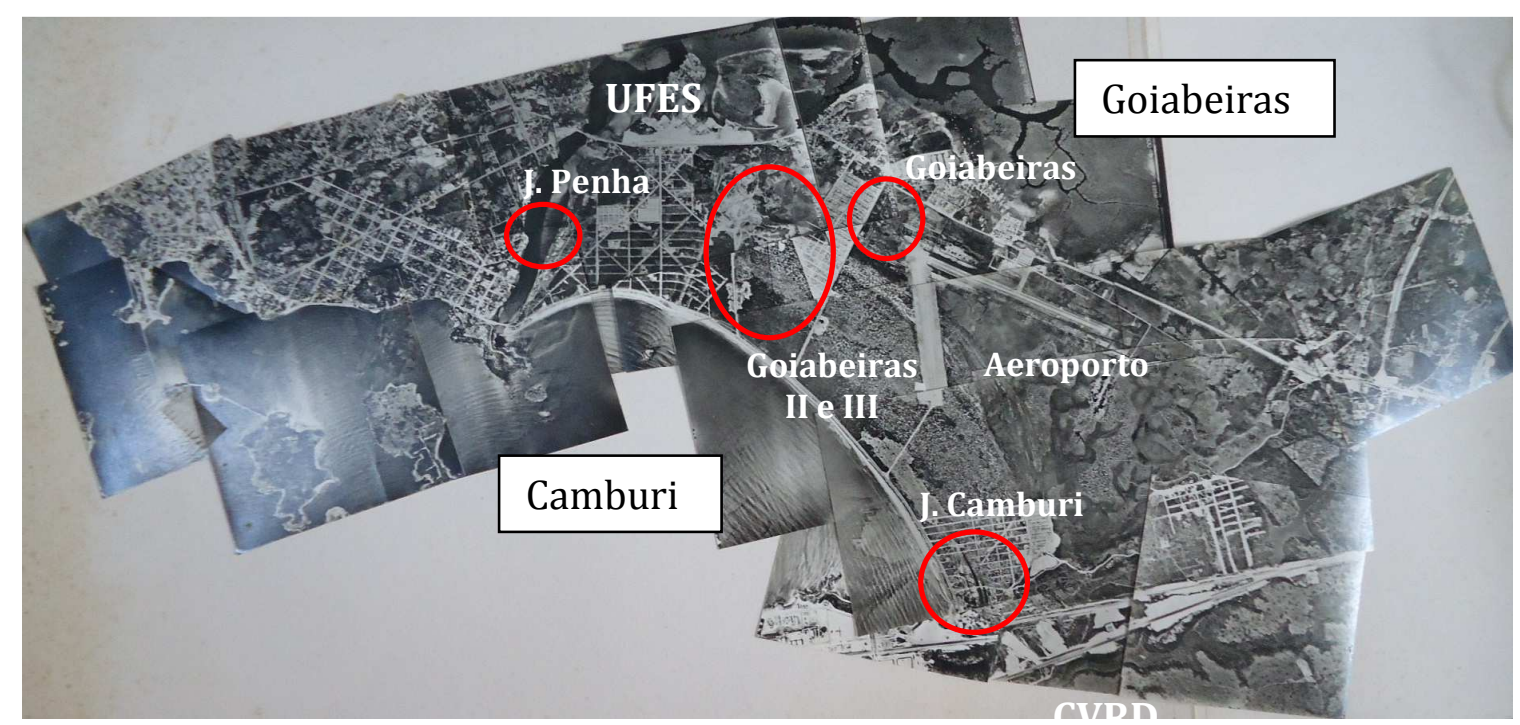

Figura 3 - Aerofotogrametria da ocupação da área continental de Vitória em 1970.

Fonte: Biblioteca do Instituto Jones dos Santos Neves com informações acrescidas pela autora. 
No âmbito nacional, em 1964, após o golpe militar e sob regime ditatorial, foi instituído o Banco Nacional de Habitação -BNH - e o Serviço Federal de Habitação e Urbanismo - SERFHAU. O primeiro, com o objetivo inicial de atender ao interesse social, distanciou-se desta função, atuando aos moldes das instituições financeiras privadas, visando lucros, passando, portanto, a destinar seus recursos à construção de habitação para população de maior renda. O segundo com a função de realizar pesquisas sobre déficit habitacional, promover o planejamento e assistir tecnicamente estados e municípios, teve também suas funções alteradas passando a encarregar-se do planejamento local, desvinculando-se da função habitacional, o que assegurou maior liberdade ao BNH (CINTRA, 1978).

A constatação através da análise de relatórios municipais, de que o município de Vitória reembolsava a Companhia de Habitação Popular - COHAB-VT -, em 1966, pela aquisição de terrenos no distrito de Goiabeiras, onde estavam sendo construídas residências para a população favelada, denota não só a natureza do território projetado para o local, como o provável baixo custo da terra, na época. Destinado à população de baixa renda, Goiabeiras não chegou a receber, no entanto, através do poder público, nesta ocasião população favelada. A COHAB-ES, "agente do SFH para as operações de natureza social" (ESPÍRITO SANTO, 1986), instituído pelo recémcriado Banco Nacional de Habitação - BNH - planejou e implementou para o local, 3 conjuntos habitacionais, contendo no total 1278 unidades residenciais de padrão construtivo regular, destinadas à população de até 3 salários mínimos (ESPÍRITO SANTO, 1986).

O primeiro destes conjuntos inicialmente denominado Goiabeiras, sendo em seguida chamado de Solón Borges, foi implantado às margens da estrada do Aeroporto, em seu lado noroeste, entre o povoado de Goiabeiras e o aeroporto. O conjunto contava com 284 unidades e foi concluído em 1966. O segundo, Goiabeiras II, foi implantado junto ao povoado, às margens da avenida Ponta de Tubarão que ligava Goiabeiras à praia e limitava a área destinada ao aeroporto. Este segundo conjunto foi concluído em 1969 e contava com 569 unidades, contendo casas térreas de 2 quartos com $35 \mathrm{~m}^{2}, 41 \mathrm{~m}^{2}$ e $43 \mathrm{~m}^{2}$ e de 3 quartos com $50 \mathrm{~m}^{2}$. O terceiro conjunto, Goiabeiras III, localizado a sudeste e contíguo a Goiabeiras II, ao longo da mesma avenida, limita-se também, com a área do aeroporto e foi concluído em 1972. Este conjunto conta com 425 unidades, compreendendo casas térreas de 2 quartos com $43 \mathrm{~m}^{2}$ e de 3 quartos com $46 \mathrm{~m}^{2}$ e $51 \mathrm{~m}^{2}$. Ao que parece, estes dois últimos conjuntos são partes de um projeto único, executado em duas etapas, visto compartilharem dos mesmos equipamentos comunitários, além da "semelhança do 
traçado e a contiguidade físico-espacial" (SANTOS e GOMES, s/d), permitindo inclusive a denominação única de Bairro República. Os três conjuntos Goiabeiras, distantes da cidade, das atividades de comércio e serviço e praticamente cercados de vegetação, foram então instalados no limite da área destinada ao aeroporto, já na época, com cerca de 20 anos de funcionamento, a despeito da incompatibilidade entre estes usos. Os riscos maiores parecem incidir sobre Goiabeiras II, localizado a poucos metros e na direção da pista de pouso e decolagem.

Simultaneamente ou, em consequência da implantação pelo poder público destes conjuntos habitacionais, houve em Goiabeiras o surgimento de outros conjuntos e de uma série de pequenos loteamentos, com ou sem denominação específica, ou adquirindo inicialmente, o nome do proprietário das terras, mas todos, sob a referência territorial de Goiabeiras. Verifica-se então, que a designação historicamente atribuída ao povoado Goiabeiras, e demarcada pontualmente em mapas do município na década de 1930 e 1940, encontrava-se nesta ocasião, já estendida não só à circunvizinhança dos conjuntos habitacionais, mas à regiãopercurso Estrada do Aeroporto, abrangendo o campus universitário da UFES (também chamado de Campus de Goiabeiras) e o aeroporto (também chamado, aeroporto de Goiabeiras, mesmo sendo o único de Vitória). Nota-se ainda, através do projeto de Goiabeiras III, a extensão do território de Goiabeiras para além da Estrada do Aeroporto, seguindo rumo à praia, que já se encontrava por sua vez, mais próxima da caracterização territorial de Camburi.

De modo semelhante, Cambury, que era indicado também pontualmente, naqueles mesmos mapas, ao final da praia de Maruhype, a esta época, era já, denominação estendida não só à Vila Balneário de Camburi, mas ao loteamento da área situada no outro extremo da praia, limitando-se com o Canal da Passagem e a estrada do aeroporto. Tendo como base, então, o traçado viário deste loteamento Camburi, projetado em 1952, o Instituto Brasileiro do Café - IBC - "comprou, em 1960, uma área de 27.661,50 m²" (COLODETTI e BARROS, 1988), para a construção de armazéns de estocagem de café. O local na ocasião, foi considerado adequado a esta finalidade, visto a facilidade de escoamento do produto através da estrada do aeroporto, a relativa proximidade do porto e o baixo custo da terra na região, que era ainda afastada do núcleo urbano. Concluídos então em 1962, os armazéns do IBC constituíram-se nas primeiras edificações do bairro, ocupando três quadras de localização central, inclusive os trechos de vias existentes entre elas.

Em 1969, próximo aos armazéns do IBC, a construtora C. R. Guimarães construiu, em área de cerca de $18.000 \mathrm{~m}^{2}$, o conjunto residencial Jardim da Penha, 
composto de 106 residências duplex, semigeminadas (PAOLIELO, 1977). Trata-se do reloteamento de duas quadras do bairro, transformadas em dez, com lotes medindo $9,10 \mathrm{~m} \times 16,00 \mathrm{~m}\left(136 \mathrm{~m}^{2}\right)$, para as quais foram projetadas 106 unidades de $50,34 \mathrm{~m}^{2}$, destinadas a população "de renda média/baixa" (BASTOS et al., 1992). Próximo a este conjunto, também em 1969, o INOCOOP-ES adquiriu $44.000 \mathrm{~m}^{2}$ para a construção de conjuntos habitacionais (COLODETTI e BARROS, s/d), tendo para esta finalidade, orientado a formação de cooperativas.

Próximo à área originalmente conhecida com Cambury, ao norte da Vila Balneário, foram construídas em 1967, inicialmente 100 residências e logo em seguida mais 101, pela Imobiliária Camburi (ARAÚJO, 1991), conjunto que passou a ser denominado de Jardim Camburi.

Assim, a região de Camburi, já estendida à praia, passou a inserir-se no contexto urbano de Vitória, como área residencial, através de dois focos de ocupação: Jardim Camburi (1967) e Jardim da Penha (1969). Esta inserção ocorreu, portanto, somente, a partir da década de 1960, a despeito de haver para o local, territórios idealizados pelo menos desde o final da década de 1920.

Neste sentido, foi possível perceber, distinções entre os territórios projetados no passado e os executados nesta ocasião, mesmo que sobre o mesmo traçado urbanístico. A imaginada Villa-Balneária, que equiparava Cambury a um reduto de férias, como Guarapari, além de não ter contado de fato, com os elementos de projeto que a caracterizava, distinguia-se sobremaneira da realidade dos Jardins Camburi e da Penha, conjuntos residenciais, como já mencionado, de padrão construtivo "regular" e destinados à "população de renda média/baixa".

Cabe, porém, assinalar que, se por um lado, a ocupação da área continental de Vitória em relação aos territórios idealizados, teria ocorrido, tardiamente, por outro lado, observa-se a sua realização neste período, antes da saturação da densidade na ilha de Vitória, contrariando recomendações já mencionadas, de adensamento da área insular, mesmo através de aterros, anteriormente à expansão da área urbana pelo continente (NOVAES, 1931).

Ocorreu que, enquanto o município investia na urbanização dos aterros já realizados na Ilha do Príncipe, Esplanada da Capixaba e Bento Ferreira, respectivamente a oeste, sul e sudeste da ilha, e planejava a execução do aterro da Enseada do Suá, previsto desde a década de 1930 (NOVAES, 1931), Vitória passou a receber o impacto do êxodo rural, estimulado em grande medida pelo programa de erradicação de cafezais (1962-1966 e 1966-1967) e do processo de industrialização que atingia na ocasião a microrregião de Vitória (ROCHA e MORANDI, 1991).

URBANA, V.6, no 8, jun.2014 - Dossiê: Cidade e Habitação na América Latina - CIEC/UNICAMP 
Ademais, as características físicas e locacionais, requeridas naquele momento por atividades como a UFES e a CVRD, foram encontradas no continente, passando a impor urgência na extensão de serviços e infraestrutura urbana naquele sentido. Outro fator que parece ter alimentado a expansão de Vitória através de sua área continental, teria sido o interesse privado no mercado de terras, que se tornou significativo apenas a partir da década anterior, quando as terras de Camburi foram enfim, loteadas, ou seja, preparadas para a comercialização.

Entretanto, o interesse de empresas particulares na promoção da ocupação de Camburi só se realizou com a implantação de empreendimentos públicos diversos, estes sim, pioneiros na inserção do território continental no contexto urbano de Vitória. Como já citado, entre eles estão o aeroporto (de Goiabeiras) em 1946, os armazéns do IBC em 1962, o porto de Tubarão e a CVRD em 1966, os conjuntos residenciais da COHAB-ES (Goiabeiras I, II e III) em 1966, 1969 e 1972 e o campus universitário da UFES (ou de Goiabeiras) em 1969 (projetado desde 1967).

Embora de proporções distintas, tratam-se, em todos os casos, de empreendimentos de grande porte, que passariam gradativamente a gerar maior circulação de tráfego e de pessoas na região continental de Vitória, além de serem necessariamente atrativos de infraestrutura urbana pública. É possível que, a certeza quanto à implantação destes serviços pelo poder público, e a expectativa de crescimento da demanda por habitação, que já se verificava, tenham então, estimulado a iniciativa particular a investir em Camburi. Observa-se também, que os empreendimentos imobiliários mesmos os particulares, surgiram apenas na segunda metade da década de 1960, após, portanto a instituição do BNH.

\section{Considerações finais}

Do exposto, constatou-se então, que o território edificado no distrito de Goiabeiras, envolvendo toda a área continental do município, na década de 1960, abrigou inicialmente, atividades não residenciais cujas características, inviabilizavam a implantação das mesmas na ilha, mesmo com os aterros já existentes e os projetados. Simultaneamente, ou imediatamente em seguida, foram inseridos os conjuntos residenciais, que junto à vegetação e àqueles empreendimentos, passaram a compor a periferia do município. O caráter serial de sua arquitetura, as pequenas dimensões de lote e de área construída, e a renda da população a que estes conjuntos se destinavam, são aspectos que contribuem para entendimento do tipo de território em formação no continente. Entretanto, estas mesmas características, que diante do meio urbano de Vitória, igualavam os territórios de Goiabeiras e Camburi, se 
destacadas e comparadas, podem também, sugerir desde já, distinção entre eles: o primeiro, mais exposto aos riscos e ruídos, pela proximidade do aeroporto, contando em grande parte, com lotes e áreas edificadas menores, construídos pelo poder público e destinados a população de até 3 salários mínimos; o segundo, construído pela iniciativa privada, devendo atender portanto à população de maior renda e no caso de Jardim da Penha, já diferenciando-se dos demais, através da proposição arquitetônica de residências duplex. Observa-se também, a denominação "jardins" diferenciando os territórios de Camburi dos de Goiabeiras. Tendo em vista não corresponder a qualquer atributo de projeto, o termo conferia, então, "status" a Camburi. Há ainda, um elemento diferenciador, que antecede a ocupação: refere-se à natureza e à cultura local, que valoriza a praia (Camburi) em detrimento do mangue (Goiabeiras).

Buscando então tecer relações entre este processo e o ocorrido em contexto nacional, salienta-se que os conjuntos habitacionais, na ocasião, unifamiliares, seguiam, como já indicado, as diretrizes lançadas pelo governo federal por meio do Sistema Financeiro de Habitação, logo após o golpe militar de 1964 (CINTRA e HADDAD, 1978; SCHMIDT, 1983).

A construção do campus universitário da UFES fora da ilha e distante do centro político e administrativo, também seguiu uma lógica instituída pelo governo militar durante a década de 1960 em várias capitais brasileiras, entre outros aspectos, neutralizando a ação organizativa da classe universitária na resistência ao sistema autoritário estabelecido.

A instalação de um novo porto, na Ponta de Tubarão, deu sequência à manutenção da vocação portuária da cidade, inaugurando possibilidades mais arrojadas de exportação e importação e de diversificação de produtos, ao oferecer alternativas para a ancoragem de embarcações de grande porte, incompatíveis ao acesso pela estreita baía, ao porto do Centro.

Esta ocupação, tanto dos conjuntos como dos grandes equipamentos, promovida na década de 1960 ocorreu de forma descontínua no território, realçando seu caráter valorativo e favorecendo o caráter especulativo da ação imobiliária. Isso pode ser percebido de modo mais evidente acompanhando-se a ocupação das áreas intersticiais por conjuntos multifamiliares durante a década de 1970 e de empreendimentos imobiliários para classe econômica mais elevada nos anos de 1980, sempre seguindo à política habitacional nacional, amparada pelo Banco Nacional de Habitação. 
Deste modo, a despeito das políticas públicas empreendidas em Vitória na década de 1960 terem se distanciado do alcance social a elas inerente, especialmente no caso da política habitacional e ter se mostrado articulada aos ideais centralizadores do governo federal, não se pode negar a importância destas na estruturação urbana e metropolitana da capital e na inserção do estado do Espírito Santo em circuito econômico mais amplo, acompanhando a dinâmica nacional e internacional.

\section{Referências}

ARAÚJO, J. C. S. de. Proposta de Desenho Urbano bairro Mata Atlanta. Vitória: Departamento de Arquitetura e Urbanismo da Universidade Federal do Espírito Santo. Projeto de Graduação, 1991.

BASTOS, F. B. N., MATTOS, R. M. de e GONÇALVES, S. N. L. Análise dos conjuntos habitacionais em Jardim da Penha. Vitória: Departamento de Arquitetura e Urbanismo da Universidade Federal do Espírito Santo. Planejamento Urbano IV. 1992.

BRASIL. Projeto do II Plano Nacional de Desenvolvimento 1975-1979. 1974.

CAMPOS JÚNIOR, C. T. O Novo Arrabalde. Vitória: PMV, Secretaria Municipal de Cultura e Turismo, 1996.

CINTRA, A. O. Planejando as cidades: política ou não política. In: CINTRA, A. O.; HADDAD, P. R. (org.). Dilemas do Planejamento urbano e regional no Brasil. Rio de Janeiro: Zahar Editores, 1978.

COLODETTI, M. P. e BARROS, R. V. de. Reutilização dos armazéns do IBC no Bairro de Jardim da Penha. Vitória: Departamento de Arquitetura e Urbanismo da Universidade Federal do Espírito Santo. Projeto de Graduação, 1988.

COSTA, R. B. Expansão Urbana da área norte de Vitória - 1970/1987. Vitória: Centro Cultural de Estudos e pesquisas do Espírito Santo, s/d.

ESPÍRITO SANTO, Coordenação Estadual do Planejamento. Instituto Jones dos Santos Neves. Estudos básicos referentes à questaão da habitação - intervenção estatal no processo habitacional (versão preliminar). Vitória, jul. 1986. (Estudos para definição da política habitacional para o Estado do Espírito Santo).

FREITAS, J. F. B. Aterros e decisões políticas no município de Vitória: efeito cascata. In: Anais do VIII Seminário de História da Cidade e do Urbanismo. Niterói: ARQ.URB/UFF, PPGG/GEO/UFRJ , IPPUR/UFRJ e PROURB/FAU/UFRJ., 2004. v. 1. p. 117.

MENDONÇA, E. M. S. (Trans) formação planejada de territórios urbanos em Vitória (ES): o bairro Camburi. São Paulo, 1995. Dissertação (mestrado) Faculdade de Arquitetura e Urbanismo, Universidade de São Paulo. 
MENDONÇA, E. M. S.; FREITAS, J. F. B.; CAMPOS, M. M.; PRADO, M. M. e ALMEIDA, R. H. de. Cidade Prospectiva: o projeto de Saturnino de Brito para Vitória. Vitória: EDUFES; São Paulo: Annablume, 2009.

NOVAES, H. e de. Plano de Urbanização de Vitória. Rio de Janeiro, 1931. In: BRÍGIDO, L. R. O município de Vitória sob o regime revolucionário - Triênio 19301933. Rio de Janeiro: Oficinas Alba Gráficas, s/d.

NOVAES, M. S. História do Espírito Santo. Vitória: Fundo Editorial do Espírito Santo, s/d.

OLIVEIRA, J. T. História do Estado do Espírito Santo. 2a ed. Vitória: 1975.

PAOLIELO, A. M.; PERUZZO, D.; PIZZIOLO, R. L.; PASOLINO JÚNIOR, H. e LIMA, W. M. Estudos de conjuntos habitacionais - visão sociológica. Vitória: Comissão nacional de regiões metropolitanas e política urbana - CNPU e Fundação Jones dos Santos Neves - FJSN, 1977.

ROCHA, H. C.; MORANDI, A. M. Cafeicultura e Grande Indústria: a transição no Espírito Santo - 1955-1985. Vitória: Fundação Ceciliano Abel de Almeida, 1991.

SANTOS, S. C. e GOMES, V. Goiabeiras II e III. Vitória: Departamento de Arquitetura e Urbanismo da Universidade Federal do Espírito Santo. Planejamento Urbano IV. s/d.

SCHMIDT, B. V. O Estado e a política urbana no Brasil. Porto Alegre: Editora da Universidade, UFRGS, LePM, 1983.

VILLAÇA, Flávio. Espaço intra-urbano no Brasil. São Paulo: Studio Nobel, FAPESP, Lincoln Institute, 1998. 